\title{
Modelling and visualisation of material flow in friction stir spot welding
}

\author{
Aidan Reilly ${ }^{a}$, Hugh Shercliff ${ }^{a}, *$, Yingchun Chen ${ }^{b}$, Philip Prangnell ${ }^{\mathrm{b}}$ \\ a Department of Engineering, University of Cambridge, Trumpington St, Cambridge CB2 1PZ, UK \\ ${ }^{\mathrm{b}}$ Materials Science Centre, School of Materials, University of Manchester, Grosvenor Street, Manchester M13 9PL, UK
}

\section{A R T I C L E I N F O}

\section{Article history:}

Received 30 March 2015

Received in revised form 17 June 2015

Accepted 18 June 2015

Available online 23 June 2015

\section{Keywords:}

Friction stir spot welding

Dissimilar materials

Aluminium alloys

Galvanised steel

Automotive alloys

Process modelling

\begin{abstract}
A B S T R A C T
The material flow in friction stir spot welding of aluminium to both aluminium and steel has been investigated, using pinless tools in a lap joint geometry. The flow behaviour was revealed experimentally using dissimilar $\mathrm{Al}$ alloys of similar strength. The effect on the material flow of tool surface features, welding conditions (rotation speed, plunge depth, dwell time), and the surface state of the steel sheet (un-coated or galvanized) have been systematically studied. A novel kinematic flow model is presented, which successfully predicts the observed layering of the dissimilar Al alloys under a range of conditions. The model and the experimental observations provide a consistent interpretation of the stick-slip conditions at the tool-workpiece interface, addressing an elusive and long-standing issue in the modelling of heat generation in friction stir processing.
\end{abstract}

(C) 2015 Elsevier B.V. All rights reserved.

\section{Introduction}

Multi-material structures in the automotive industry can offer greater mass efficiency at an acceptable cost. There is also a trend in the industry to move towards thinner gauges and stronger aluminium alloys and steels, again to save weight. The development of techniques for spot joining aluminium alloys to thin steel sheet has thus grown in importance. Resistance spot welding (RSW) is currently the predominant method for joining sheet-based car bodies in automotive manufacturing, because it is a fast, versatile, and easily automated process. But Connolly (2007) notes that there are major barriers to the adoption of RSW for aluminium intensive vehicles, including high energy consumption and the requirement for frequent electrode maintenance. Moreover, in aluminium to steel welds, Qiu et al. (2009) and Sakiyama et al. (2013) have shown that, due to the presence of a transient liquid phase, RSW is prone to the formation of a thick intermetallic interlayer which can seriously deteriorate joint performance. Friction stir spot welding (FSSW) is a relatively novel joining technology, emerging as a possible alternative to RSW for joining aluminium body structures in the automotive industry. The process requires far less energy than RSW ( $\sim 2$ as opposed to $\sim 50 \mathrm{~kJ} /$ weld $)$. More importantly, as discussed

\footnotetext{
* Corresponding author.

E-mail address: hrs@eng.cam.ac.uk (H. Shercliff).
}

by Briskham et al. (2006), it reduces intermetallic formation by avoiding liquid phase reactions. However, the relatively long welding cycle and lower strength of dissimilar joints are disadvantages, inhibiting the widespread adoption of FSSW in automotive manufacturing. Briskham et al. (2006) and Sato et al. (2009) suggest that process cycle times for dissimilar FSSWs are typically three to ten seconds, or even greater, compared to much less than $1 \mathrm{~s}$ for RSW. Shortening the weld cycle is thus necessary to allow wider scale implementation of FSSW in automotive manufacturing.

The Manchester group in this project (Chen et al. (2010); Bakavos and Prangnell (2009); Bakavos et al. (2011)) have shown the feasibility of producing dissimilar aluminium to steel friction stir spot welds in thin automotive sheet ( $1 \mathrm{~mm}$ thick). Welds between 6111-T4 aluminium sheets were produced successfully by Bakavos and Prangnell (2009) and Bakavos et al. (2011), using optimised pinless tools, with a modest degree of profiling on the tool shoulder. Fig. 1 shows the typical process geometry, with the three tools used in the current work. The cycle time was less than one second, and high lap-shear strengths were achieved by the joints failing in nugget pull-out mode. In comparison, for FSSW of dissimilar aluminium to steel, Chen et al. (2010) found that it was difficult to achieve high strength joints within one second, particularly with zinc coated steel grades. Profiled pinless tool designs remained most effective for thin, dissimilar-sheet material combinations. da Silva et al., 2010 and Watanabe et al., 2010 have used a similar tool configuration for FS spot welding steel to aluminium. 
Table 1

Nominal compositions of the materials welded in this investigation.

\begin{tabular}{|c|c|c|c|c|c|c|c|c|c|c|c|c|c|}
\hline \multirow[t]{2}{*}{ Alloys } & \multicolumn{13}{|c|}{ Chemical compositions (wt\%) } \\
\hline & $\mathrm{Al}$ & $\mathrm{C}$ & $\mathrm{Cu}$ & $\mathrm{Cr}$ & $\mathrm{Fe}$ & $\mathrm{Mg}$ & Mn & Mo & $\mathrm{Si}$ & $\mathrm{Ti}$ & $\mathrm{Zn}$ & $\mathrm{P}$ & $\mathrm{S}$ \\
\hline Al 6111 & Bal. & $<0.01$ & 0.75 & $<0.01$ & 0.25 & 0.75 & 0.2 & $<0.01$ & 0.69 & 0.04 & 0.02 & - & - \\
\hline Al 6082 & Bal. & - & 0.1 & 0.25 & 0.5 & $0.6-1.2$ & $0.4-1$ & - & $0.7-1.3$ & 0.1 & 0.2 & - & - \\
\hline DC04 & - & 0.08 & - & - & Bal. & - & 0.4 & - & - & & & 0.03 & 0.03 \\
\hline DX54Z & 0.01 & 0.01 & - & - & Bal. & - & 0.3 & - & - & 0.125 & - & 0.03 & 0.035 \\
\hline
\end{tabular}

Studies of FSSW, such as Bozzi et al. (2010) and Lee et al. (2009), have largely focussed on microstructural and property characterisation, including the formation of intermetallic reaction layers at the weld interface in aluminium-steel joints. In contrast, while investigations by Uematsu et al. (2010) and Coelho et al. (2008) have explored the influence of the material flow behaviour on weld formation, their limited direct observation make interpretation difficult. In this study we have devised an experimental technique to reveal the material flow in FSSW of aluminium, in similar and dissimilar welds to steel. The aim is to understand the development of the deformation zone, and how this depends on the process variables (rotation speed, plunge depth and weld time), and to study the effect of the contact conditions (between workpiece and tool, and between the top and bottom sheets). The experiments are interpreted via a simple kinematic flow model that sheds new light on the metal flow and heat generation, exploited by Jedrasiak et al. (2013) in their numerical analyses of FSSW.

\section{Experimental procedure}

The materials used in this study were $0.93 \mathrm{~mm}$ thick $6111-\mathrm{T} 4$ aluminium and $1 \mathrm{~mm}$ thick DC04 (un-galvanized) and DX54Z (galvanized) low carbon steel sheet, supplied by Jaguar Land Rover and Corus UK. Their chemical compositions are summarized in Table 1. Bakavos and Prangnell (2009) and Bakavos et al. (2011) provide details of the weld set-up and clamping arrangements. Rectangular samples of dimensions $100 \times 25 \mathrm{~mm}$ were lap-welded in displacement control, with the weld located at the centre of a 25 mm overlap region (Fig. 1a). The top sheet in contact with the tool was always aluminium. Three pinless FSSW tools of diameter $10 \mathrm{~mm}$ were used (Fig. 1b): a flat featureless tool, made of tool steel, and two "fluted"

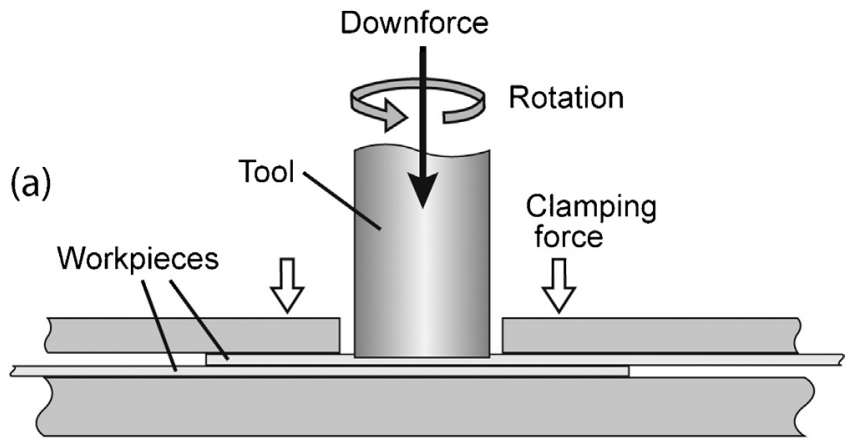

(b)
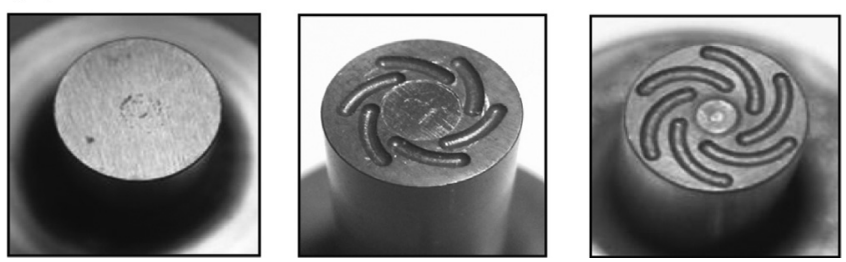

Fig. 1. Friction stir spot welding with pinless tools: (a) schematic of process, showing overall lap geometry; (b) three tool profiles used: flat, short flute, long flute. tools with 6 symmetrical short or long grooves, designed to rotate against the curve of the flute to drive material radially inwards. A variant of the flat tool was made from cemented WC with a PVD diamond coating. This was found to be necessary for welding the Al alloy to Zn coated DX54Z steel, to avoid sticking between the tool and the $\mathrm{Al}$ sheet, under the different process conditions needed for this material combination.

Chen et al. (2010), Bakavos and Prangnell (2009), and Bakavos et al. $(2010,2011)$ describe the procedures conducted for lap shear testing of the joints, measuring peak failure load and overall failure energy (i.e., the area under the load-displacement curve), since the latter is found to correlate best with the observed failure mechanism. Optimum process conditions led to a "pullout" failure with higher failure energy, whereas interfacial failure was associated with low fracture resistance. Empirical trials resulted in the following experimental parameter ranges for Al 6111 welded to itself or to uncoated DC04 steel: rotation speed, $120-2000 \mathrm{rpm}$; plunge rate, $100 \mathrm{~mm} / \mathrm{min}$, retraction rate $50 \mathrm{~mm} / \mathrm{min}$; shoulder plunge depth, 0.1-0.7 mm; nominal dwell time, $0.5-1 \mathrm{~s}$. The total weld cycle time included the additional nominal times spent in the plunge and retraction stages (usually less than $2 \mathrm{~s}$ in total). Typical optimum conditions for Al to steel with a $1 \mathrm{~s}$ dwell time were $1600 \mathrm{rpm}$ with a plunge depth of $0.5 \mathrm{~mm}$. For Al 6111 to Zn coated DX54Z steel, it was found that the process window was very limited, requiring plunge and retraction rates to be more than 10 times slower in order to avoid tool sticking and weld failure. As a result, total weld times increased to the order of $10 \mathrm{~s}$. Table 2 summarises the lap shear strengths and failure energies for the optimised conditions in each case. Joints between Al 6111 and uncoated DC04 steel significantly underperformed compared to similar Al 6111-6111 welds, particularly in terms of joint failure energy, with higher strength being achieved with a fluted tool than with a flat tool. In contrast, Al 6111 to Zn coated DX54Z steel shows comparable strength to 6111-6111, with $65 \%$ of the failure energy, but at the penalty of a much slower weld cycle.

Material flow was studied for the ranges of process conditions used to identify the optimum lap shear performance, with the aim of understanding how the flow influenced the welding mechanism and joint quality. Metal flow in the deforming Al layers was revealed via a contrast technique. Strips of identical thickness were cut from a similar aluminium alloy, 6082, which has a lower copper content than 6111. The objective in choosing 6082 was to have a similar deformation response, but with the two copper contents providing differential etching and colour contrast in micrographs. Prior to welding, the 6082 alloy was aged to the same hardness as the 6111T4 material (80HV), though it is recognised that the two alloys may diverge in their hot flow properties as they heat up during welding. To observe the flow, welds were produced in a range of configurations, with 6082 substituted for 6111 in part of the weld zone (Fig. 2). The flow in conventional Al-Al lap welds was studied by replacing either the lower sheet with 6082 , or by a "double-butt" arrangement with a butt joint between the two Al alloys in both the top and bottom layers. For Al-steel welds, a single-butt between the Al alloys was used for the top layer. The welded joints were sectioned vertically, at right angles to the original plane of the butt interface, and characterised by optical microscopy. 
Table 2

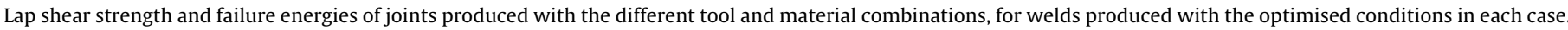
The total weld cycle time includes the nominal plunge, dwell, and retraction times.

\begin{tabular}{|c|c|c|c|c|}
\hline Material combination & Tool type & Total weld cycle time (s) & Maximum lap shear strength $(\mathrm{kN})$ & Failure energy ( $\mathrm{kN} \mathrm{mm})$ \\
\hline 6111-T4 Al/6111-T4 Al & Short flute & 1.1 & 3.4 & 7.0 \\
\hline 6111-T4 Al/DC04 steel & Flat-steel & 1.9 & 2.2 & 0.7 \\
\hline 6111-T4 Al/DC04 steel & Short flute & 1.9 & 2.8 & 1.5 \\
\hline 6111-T4 Al/DX54Z steel & Flat-WC & 10 & 3.7 & 4.6 \\
\hline
\end{tabular}

(a)

\begin{tabular}{|c|}
\hline \\
6082 \\
\hline
\end{tabular}

(b)

\begin{tabular}{|l|l|}
\hline 6082 & 6111 \\
\hline 6082 & 6111 \\
\hline
\end{tabular}

(c)

\begin{tabular}{|l|c|}
\hline 6082 & 6111 \\
\hline steel
\end{tabular}

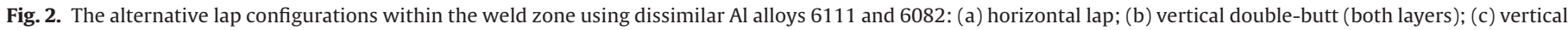
single-butt (top layer only, with steel bottom layer).

\section{Observations of material flow}

\subsection{Contrast alloys in Al-Al FSSW}

Fig. 3 shows a series of micrographs for sections through $\mathrm{Al}$ 6111-Al 6082 welds in the horizontal lap configuration, with 6082 being the bottom sheet material. For the flat tool (Figs. 3a,b) the two layers remain distinct from one another with some evidence of inter-layering of the two alloys close to the interface for the $1 \mathrm{~s}$ weld. The short flute tool produces a similar deformation pattern after $1 \mathrm{~s}$, but is distinctly different after $2.5 \mathrm{~s}$. Now the lower sheet is drawn upwards and fully penetrates the upper sheet through to the tool interface, hence enclosing a volume of the upper sheet within a ring of material formed from the lower sheet. The enclosed volume from the upper sheet is pushed downwards below the interface, and reduces in diameter, to conserve volume. Bakavos et al. (2011) describe this phenomenon in lap joints as "hooking". It is consistent with a slow circulation of material, flowing inwards radially near the top surface, driven by the flutes on the tool, and downwards through the weld centre. However, it should be recognised that the predominant flow direction remains circumferential - in the limit of sticking to the tool, the circumferential material velocity matches that of the tool at the surface.

Greater insight is obtained by comparing micrographs from identical welds with the dissimilar alloys in two different configurations. Horizontal lap and double-butt welds in Al 6111-Al-6082 are shown in Fig. 4, for $1 \mathrm{~s}$ and $2.5 \mathrm{~s}$ dwell times, using the long flute tool.

First we note from Figs. 4a,c that the long flute tool leads to hooking in a similar manner to the short flute (compare with Fig. 3c,d). But now the double-butt configuration reveals the axisymmetric material flow driven by the tool rotation. Fig. 4b shows distinct
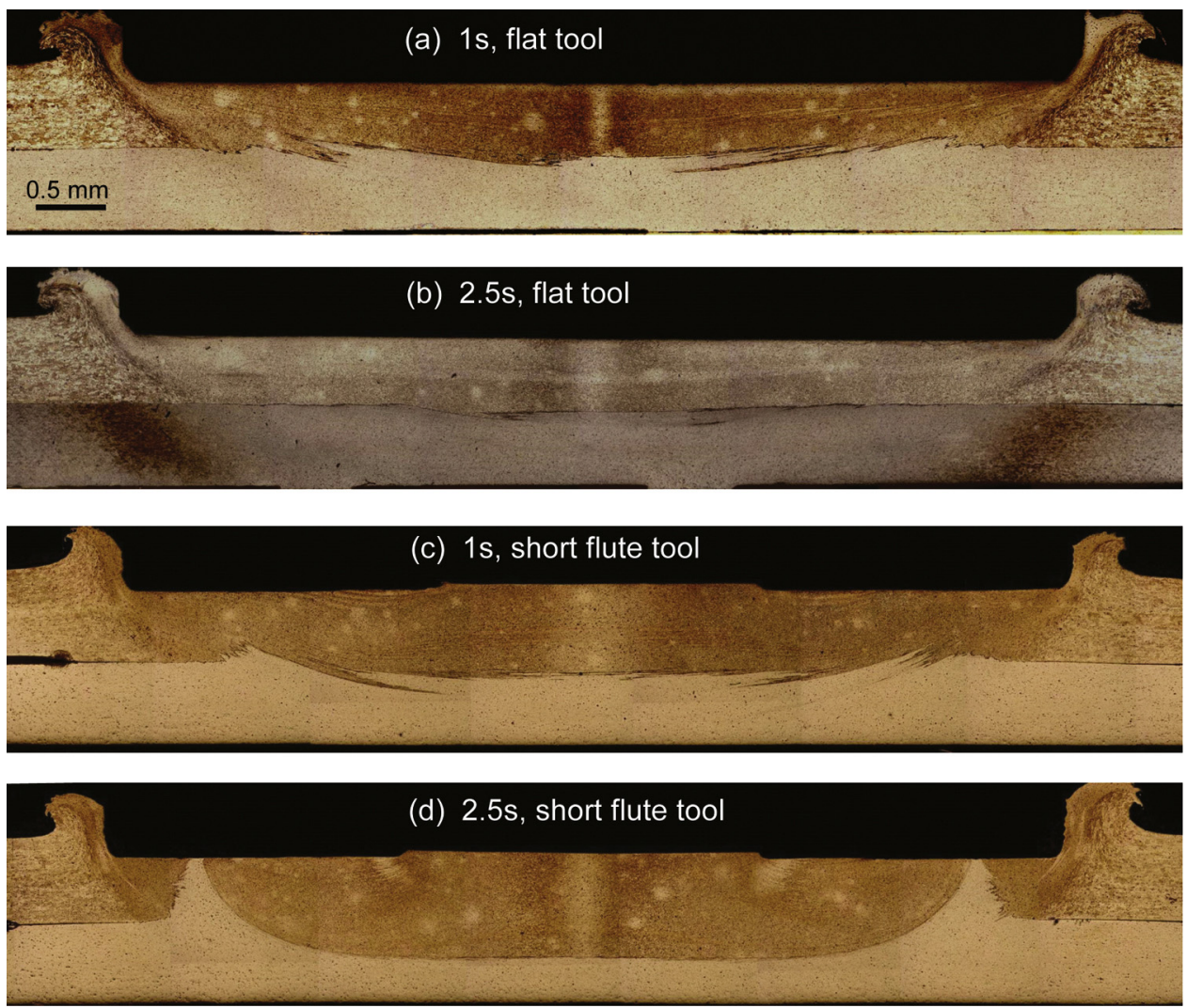

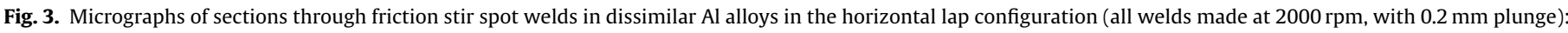
(a,b) flat tool, for dwell times of $1 \mathrm{~s}$ and $2.5 \mathrm{~s}$ respectively; (c,d) short flute tool, again for $1 \mathrm{~s}$ and $2.5 \mathrm{~s}$ respectively. 

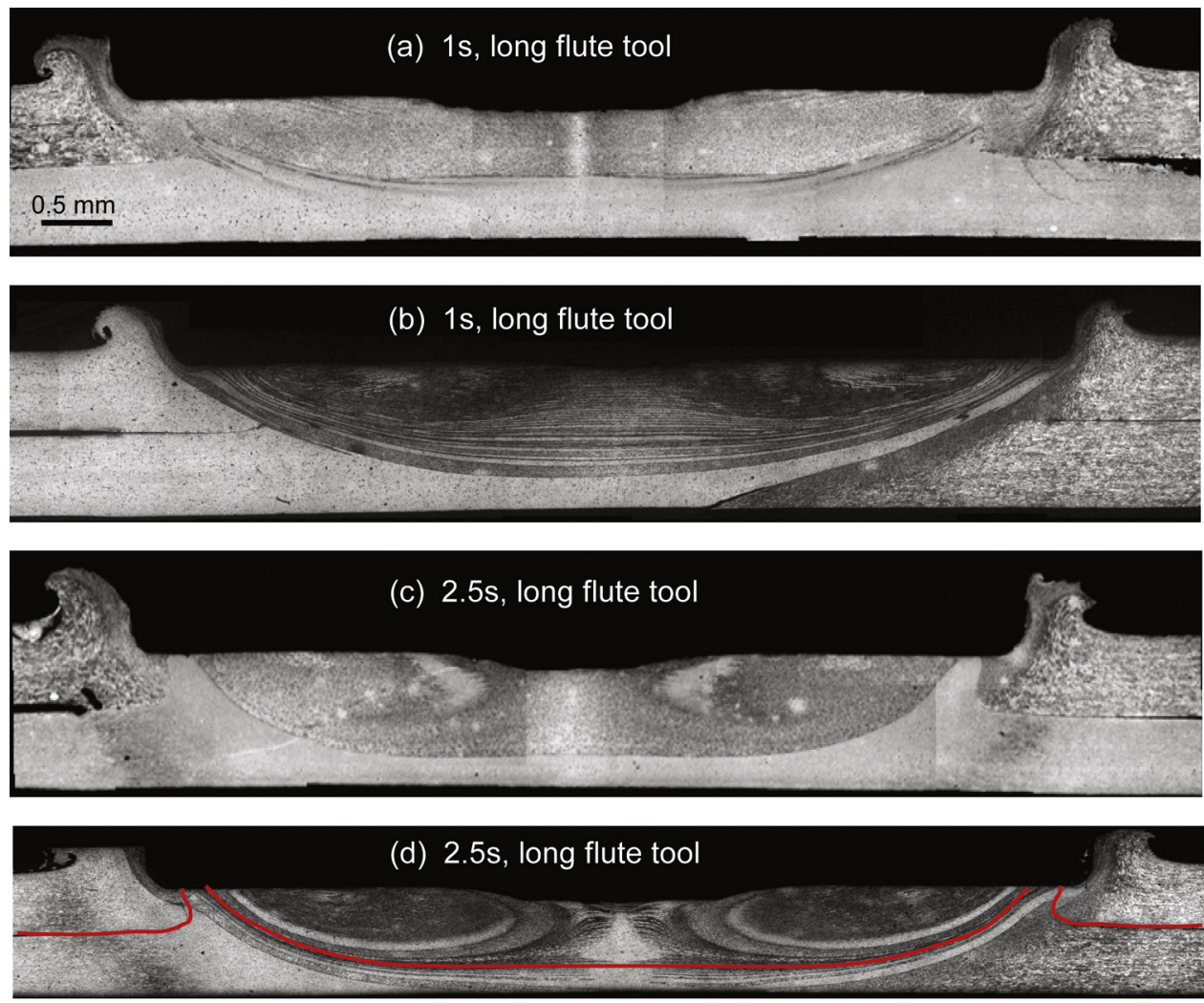

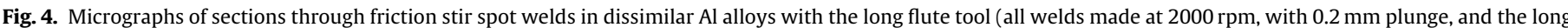

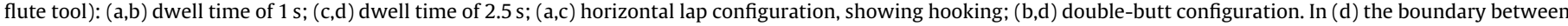
the bottom and upper sheets is superimposed, using image $(c)$.

inter-layering of the two alloys in the lower part of the deformation zone, with horizontal banding extending far up the centre of the weld. In Fig. 4d, the boundary between the original two horizontal sheets (from Fig. 4c) has been superimposed on the double-butt micrograph. The inter-layering of the two alloys is continuous within the material which was initially in the lower sheet. In contrast the top sheet is more strongly associated with the "swirl" pattern of circulating flow driven by the hooking behaviour, and this disrupts the regular layered pattern.

The micrographs of Figs. 3 and 4 demonstrate that the dissimilar alloy marker technique works well, with the overall deformation pattern being retained, regardless of the difference in the Al alloys. The deformation is complex in $\mathrm{Al}-\mathrm{Al}$ welds, particularly with the fluted tools, combining hooking between the layers and circulating radial flow, with apparent layering of material from opposing sides of the weld, within each original sheet. As will be shown below, the issue of hooking does not arise in Al-steel welds, because the lower steel sheet does not deform, so the layering behaviour has been investigated further in Al-steel welds, using the single-butt configuration with dissimilar $\mathrm{Al}$ alloys in the top layer (Fig. 2c).

\subsection{Contrast alloys in Al-Steel FSSW}

Fig. 5 shows micrographs of friction stir spot welds between $\mathrm{Al}$ (butted 6111 and 6082) and uncoated DC04 steel. Fig. 5a shows that, with a flat tool, the inter-layering extends over the entire deformation volume. As there are no features on the tool, this confirms that the layering is driven by axisymmetric flow associated with the tool rotation. With the short flute tool, the layered flow is still evident, but with the annular swirl region associated with the flute-driven flow superimposed and disrupting the layers (as was observed previously with the long flute). What is striking in both cases is that the layers of the two alloys remain so distinct, and that the layering is very symmetrical about the vertical centre-line, with each alloy mirroring the other across the weld. This layered pattern suggests that the deformation pattern in FSSW is kinematically highly constrained: the surface flow is closely related to the rotational velocity of the tool interface, while the lower face of the sheet is effectively stationary. This provides the starting point for modelling the process in the next section. Further evidence is provided by Fig. 5(c,d), which show two deeper plunge welds using the flat tool, for widely different rotation speeds, with a dwell time of $1 \mathrm{~s}$. It is clear that the layering persists in all cases, with the intense deformation zone extending beyond the edge of the tool, to conserve volume as the tool plunges further into the top sheet. What is also now apparent across all of Fig. 5 is that the number of layers increases with rotation speed, and hence with number of revolutions in a fixed dwell time. A secondary detail to note is that the layer thickness decreases progressively from the bottom of the deformation zone up to the tool interface.

The relationship between number of layers and the number of rotations was investigated by gathering data from all Al-steel welds in which the layers could reasonably be counted through the entire deformation depth. These were primarily welds using the flat tool, which produced the clearest patterns (see Fig. 5), supplemented with a few short flute welds. Plunge depths were $0.1,0.3$, or $0.5 \mathrm{~mm}$, weld dwell times mostly $1 \mathrm{~s}$ (with a few $0.5 \mathrm{~s}$ ) and rotation speeds were $300,800,1600$, and $2000 \mathrm{rpm}$. Longer duration welds and long flute welds were qualitatively similar, but the layers could not be distinguished with sufficient accuracy.

The layers were counted in "double-layers", i.e., each band of two colours, that is, half the number of interfaces between the two alloys. The reasons for this will be explained in the modelling section below. The number of layers was then compared with 

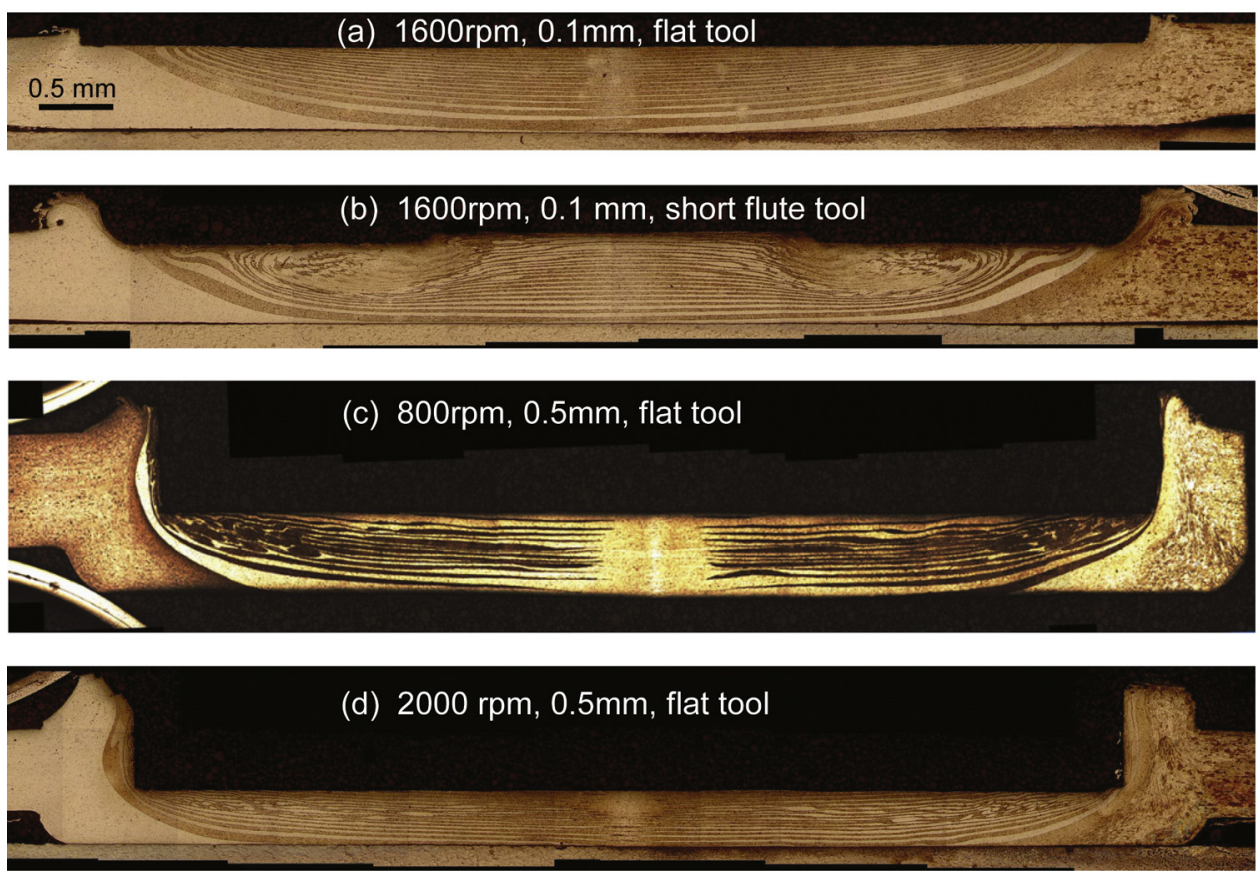

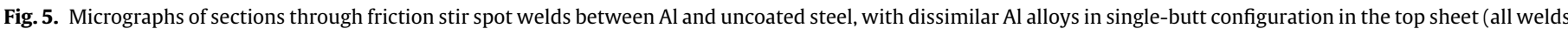

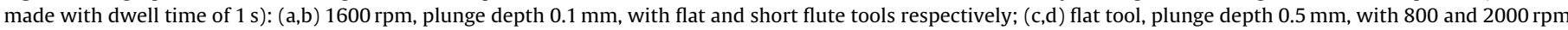
respectively.

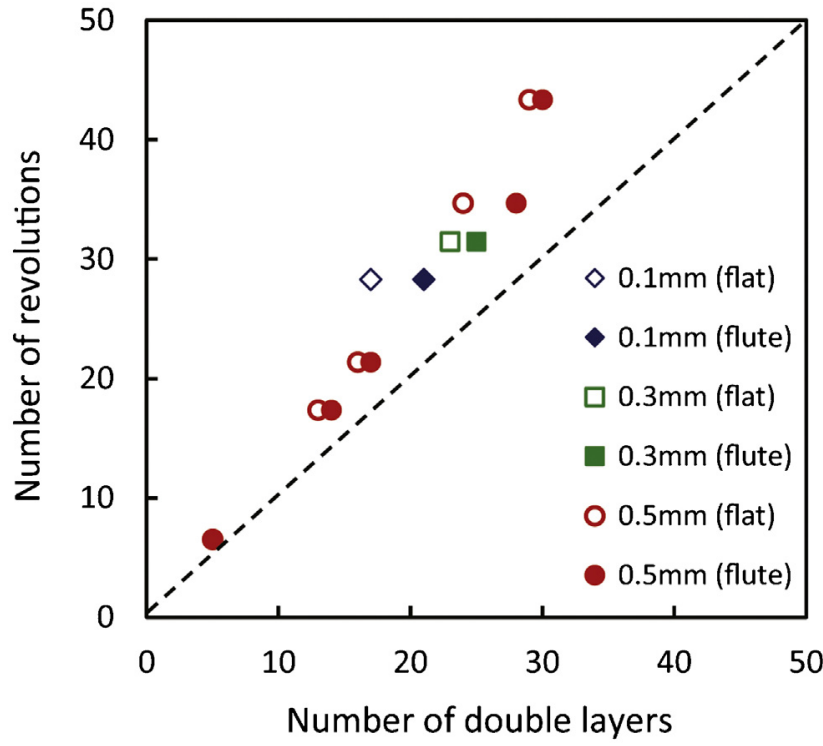

Fig. 6. The number of revolutions against the experimentally observed number of double layers formed in single-butt Al-steel DC04 welds, for a range of plunge depths, rotation speeds, dwell times and tools.

the number of revolutions the tool would make from the point of first contact to the start of retraction, i.e., the sum of the (nominal) plunge time (=depth/plunge speed) and the dwell time. Note that in practice, the resistance of the sample during the vertical plunge may reduce the plunge speed, such that the tool continues to advance to the final plunge depth throughout both plunge and dwell time.

Fig. 6 shows the number of tool rotations against the number of double-layers estimated from micrographs such as Fig. 5. The diagonal line represents equality between these two quantities.

The correlation is clear, with the number of layers being a high proportion of the number of rotations in every case, regardless of the plunge depth, rotation speed, dwell time, or tool type. As the plunge depth increases, the same number of layers is formed but the layers are compressed vertically and expanded radially by the overall forging effect of the tool. In conclusion therefore, it is proposed that every rotation is associated with the creation of a horizontal double-layer of material drawn from opposing sides of the original vertical plane through the weld centre. The close correlation confirms the kinematically constrained nature of the process, and the mechanism for formation of these layers will be revealed by modelling the process, assuming simple kinematic boundary conditions on the flow.

Finally, the sections in Al-galvanised steel welds show a complete contrast in behaviour. Fig. 7 shows two welds produced at different rotation speeds in deep plunge, long duration welds in single-butt configuration with the $\mathrm{Zn}$-coated steel. It is interesting to note that now the material layering is largely perpendicular to the weld interface, with a small dish-shaped region at the centre of the higher rotation speed weld. Detailed investigation showed that, owing to the low temperature eutectic reaction in the $\mathrm{Al}-\mathrm{Zn}$ system (stated by Murray (1986) to be $382^{\circ} \mathrm{C}$ ), melting of the $\mathrm{Zn}$ coating occurred in these welds. Hence it may be assumed to provide little or no constraint to the underside of the Al sheet. The kinematic model has therefore been used to investigate these layering patterns, by modifying the boundary condition between the workpieces.

\section{Kinematic model of material flow in FSSW}

\subsection{Basis of the model}

The experimental observations indicate that FSSW in thin sheet material is highly constrained. Metal flow takes place within a thin deformation zone defined by stationary or uniformly rotating boundaries. This suggests that the flow pattern is largely kinematically determined, so this will be investigated using a simple model that proscribes viable velocity fields, and tests their validity by simulating the welding of dissimilar Al alloys. 

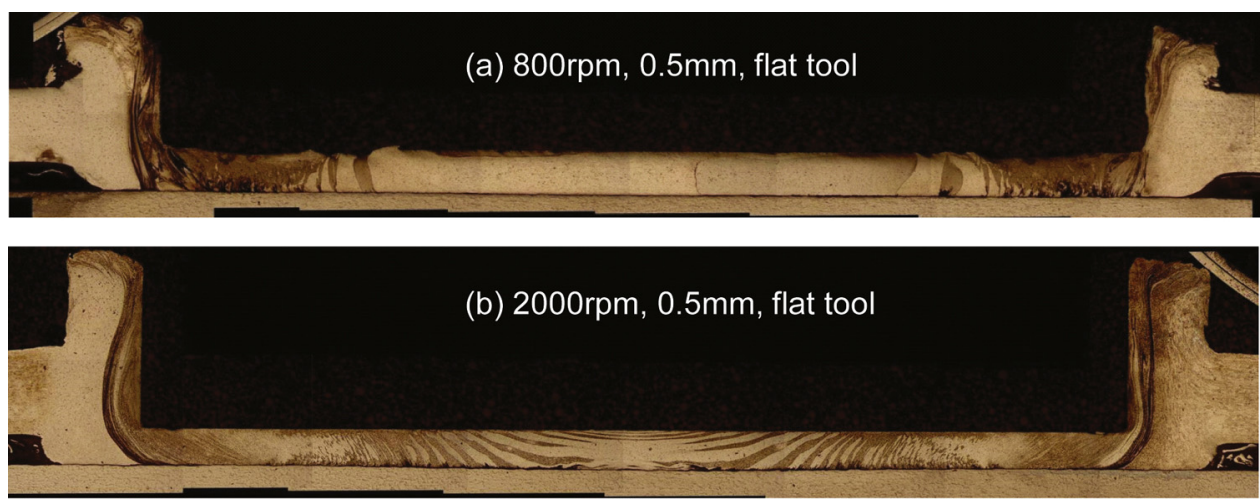

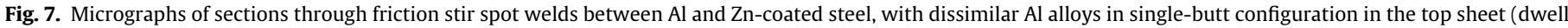
time of $1 \mathrm{~s}$ ): (a) $800 \mathrm{rpm}$ and (b) $2000 \mathrm{rpm}$.

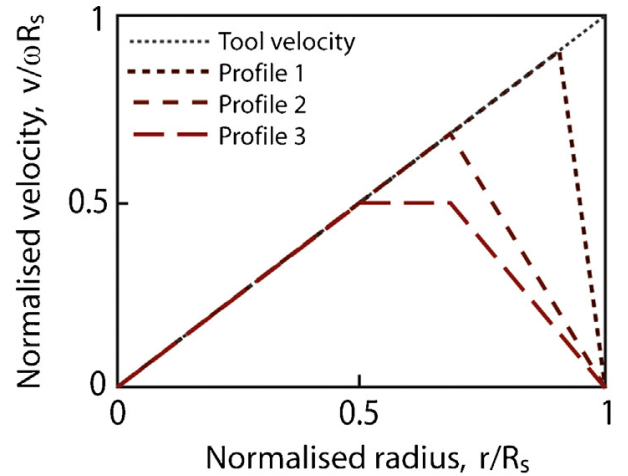

Fig. 8. Surface velocity profiles, with tool sticking to various fractions of the shoulder radius, with a surrounding region of slip.

The core assumptions of the model are as follows: (a) the steel tool and backing plate are rigid bodies; (b) the deformation volume is assumed to be a through-thickness cylinder of diameter equal to the tool diameter, with zero velocity proscribed on the cylindrical surface; (c) radial flow is negligible, as the shoulder diameter to sheet thickness ratio is of order 5-10, so radial flow is constrained by friction against the tool and backing plate; (d) metal flow is purely axisymmetric (i.e., most directly applicable to the flat tool).

The model works by imposing a radially varying angular velocity distribution to the tool-workpiece interface, and then making various assumptions about the variation of this velocity with depth, that is $v=v(r, z)$ (i.e., there is no variation with $\theta$ ). For the case of full sticking at the tool-workpiece interface, $v=\omega \times r$ for $z=0$ (the top surface). However, as noted earlier, at some radius $R_{\mathrm{S}}$ (close to the tool radius) the velocity must fall to zero, for continuity with the surrounding material. This leads to a transition region between the sticking region and the periphery, giving a slip region where the tool moves faster than the workpiece with which it is in contact. Fig. 8 shows three idealised surface velocity profiles, with progressively higher degrees of slip. For simplicity, the surface velocity profile imposed was assumed to be constant during a weld, though it could vary with time. And in the first instance, the contacts between the workpiece sheets, and between backing plate and lower sheet, are assumed to be fully sticking.

The three velocity profiles are defined by two parameters: a radius $r_{1}$ at which slipping first occurs (with full sticking taking place inside this radius), and a radius $r_{2}$ which denotes the point from which the slip regime starts to taper linearly to zero at the radius $R_{\mathrm{s}}$. For profiles 1 and $2, r_{1}=r_{2}$, giving triangular profiles (Fig. 8). The profile is assumed to be piece-wise linear between the proscribed points. The velocity profile may be expressed math-
Table 3

Definition of the slip velocity $v^{\prime}$ between the tool and workpiece for the kinematic model.

\begin{tabular}{ll}
\hline Radial region (Fig. 8) & $\begin{array}{l}\text { Slip velocity (relative velocity } \\
\text { between tool and workpiece) }\end{array}$ \\
\hline$r<r_{1}$ & $v^{\prime}=0$ \\
$r_{1}<r<r_{2}$ & $v^{\prime} \propto\left(r-r_{1}\right)$ \\
$r>r_{2}$ & $v^{\prime} \propto\left(r-r_{1}\right)+\left(\frac{r-r_{2}}{R_{s}-r_{2}}\right)$ \\
\hline
\end{tabular}

ematically in terms of the relative slip velocity $v^{\prime}$, the difference between the velocity of the tool and the surface velocity of the workpiece, as summarised in Table 3.

A further consideration is the effect of the plunge, when material is expelled laterally from beneath the tool (to conserve volume). Nominally the plunge duration is much shorter than the dwell time, though it is likely that the machine plunge velocity is retarded by the build-up of significant pressure under the tool. Again for simplicity, it is assumed that the thickness of the deforming workpiece below the tool is fixed. This is most reasonable for $\mathrm{Al}-\mathrm{Al}$ welds in which the plunge was typically only $5-10 \%$ of the total workpiece thickness. In deeper plunge welds, a radial flow should strictly be superimposed, to account for axisymmetric forging of the disc below the tool. However, it is reasonable to assume that this velocity field will be axisymmetric, and will vary uniformly with radius and depth. Hence in principle the imposed axisymmetric flow pattern in the model could be compressed vertically, and stretched radially, to account for the plunge. Reilly (2013) has shown that this does not change the first order axisymmetric behaviour, and so the effect of the plunge has not been investigated further here.

\subsection{Flow visualisation in the model}

Consider first a homogeneous cylindrical block, with a rotation applied (anticlockwise) at the top surface following one of the profiles in Fig. 8. If there is no variation in flow strength with depth (i.e., it assumed to be isothermal), this results in a uniform strain field, such that the velocity at any depth follows the same profile as that at the surface, but scaled linearly with depth, i.e., $\partial v / \partial z=\mathrm{C}_{0}$ where $\mathrm{C}_{0}$ is a constant (such that $v=0$ at the lower interface). The circumferential velocity of any material point is then defined, and hence the circumferential displacement of an initially vertical plane is known after a given time. The interface between the dissimilar alloys in the single or double butt configuration can then be tracked and defined in 3 dimensions for any given number of tool rotations, and the resulting model sectioned for comparison with the weld section micrographs.

A visualisation tool was produced using Matlab to show the final position of an initial vertical plane that passes through the axis of 


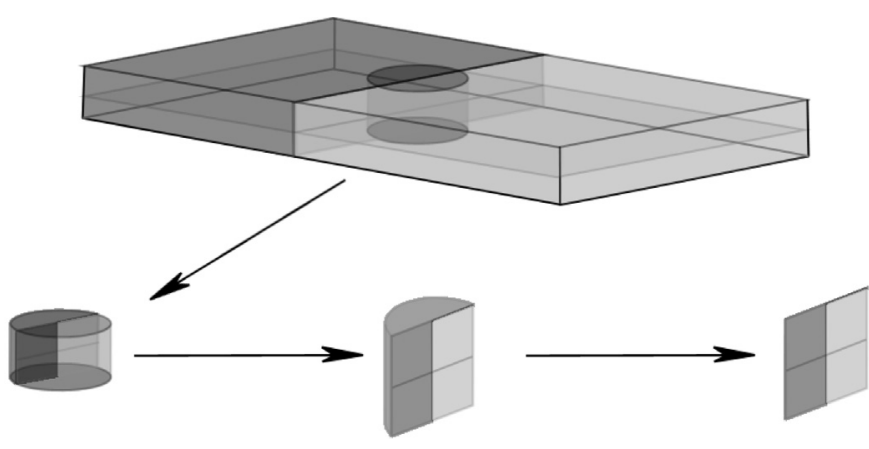

Fig. 9. Representation of the interface between dissimilar $\mathrm{Al}$ alloys in the doublebutt configuration of the kinematic model. The interface between the materials within the deforming cylinder is coloured to represent the advancing face of each alloy at the interface, for anticlockwise rotation.

the tool - see Fig. 9. First, both top and bottom workpieces to either side of the vertical plane are highlighted in different colours. Each colour therefore corresponds to one of the two Al alloys in a butt configuration, with the plane being the interface between them. Half of this vertical plane represents the advancing face of one alloy, and half of it that of the other alloy, as illustrated in the lower part of Fig. 9. Subsequent figures show the final position of this plane, such that the colour of this interface is always that of the material immediately behind the interface.

To illustrate the method, consider a homogeneous cylinder through both sheets, with a top surface velocity profile equal to $v=\omega \times r$ for all radii out to the tool radius $R_{\mathrm{s}}$ (the dotted line in Fig. 8). The velocity discontinuity at the outer edge of the cylinder is initially ignored, to convey the model concept. This case represents a condition of full sticking between the top and bottom surfaces of the cylinder, which is unconstrained on its outer curved surface, while the top rotates with respect to its stationary base. Fig. 10 shows the final position of the bi-coloured butted interface, in a series of isometric views up to 1.5 rotations. This simple approach shows clearly that rotation of the tool results in the original vertical planar interface between the dissimilar alloys being converted into a spiral 'corkscrew' by the continuous twisting of the top interface.

\subsection{Through-thickness metal flow in Al-Al and Al-steel welds}

To model real welds, the edge discontinuity in velocity must be enforced. This is illustrated first for double-butt Al-Al welds (Fig. 2b), assumed to be deforming through-thickness from the start of welding. Fig. 11a shows the isometric views found by imposing velocity profile 1 from Fig. 8 , up to 0.5 rotations. The central sticking region forms the same corkscrew shape, but the edges of the plane remain fixed, giving a smooth curved surface between the limit of sticking and the outer radius.

For joining aluminium to steel, the deformation is restricted to the top workpiece, so the model is adapted to the single-butt configuration, with no deformation in the lower layer (Fig. 2c). For Al-ungalvanised steel welds, the boundary condition at the base of the aluminium is the same as before, that is, full sticking is assumed. The result is shown in Fig. 11b, using the same interface conditions as in Fig. 11a and a half rotation. The same pattern develops with tighter spirals, as the same rotation is accommodated in half the depth - the final pattern in Fig. 11a is exactly the same as that in the top half of Fig. 11b, magnified vertically by a factor of two.

\subsection{Modelling weld sections}

The isometric view gives useful insight into the process, but sectional views provide more useful output for comparison with experimental results. These views are generated by modelling the final position of the interface as above, and then "filling in" the space behind the interfaces to give a solid model, which is then sectioned horizontally and vertically. This is why the vertical plane was coloured according to the alloy behind the interface, on each side of the weld axis. Hence starting from any point on the interface coloured for material 1 , a circumferential path back around the rotation axis all lies within material 1 , until the next interface of opposite colour is encountered and the material switches to type 2 .

Fig. 12 shows a series of three outputs from the model: isometric, top-down surface plan view, and vertical cross-section. The weld modelled is an Al-steel lap joint in the single-butt configuration, with surface velocity profile 2 from Fig. 8, and with the analysis extended to 5 rotations (equivalent to $0.15 \mathrm{~s}$ at $2000 \mathrm{rpm}$ ). The isometric and top-down views in Fig. 12 shows a central undeformed region (stuck to the tool), surrounded by nested spirals of the two alloys in the outer slip region, with the number of layers of the two alloys increasing with the number of rotations. Note that this pattern appears with zero inward flow of the material. In the crosssectional views, the alloys appear in alternate layers, once there has been at least one rotation. In the sticking region of the contact the interfaces are horizontal, consistent with the "corkscrew" form of the deformation in this region. At the edges, the interfaces curve upwards to intersect the surface (resulting in the spiral pattern of layers). It is also observed that the sections are mirror images about the centre-line between the two different Al alloys, as observed experimentally (Fig. 5a,b).

The cross-sections show that once the layered pattern is established, the number of interfaces between the two materials is equal to exactly twice the number of rotations of the tool. Hence the number of double layers (one of alloy 1 and one of alloy 2) is equal to the number of rotations - which explains why this parameter was used in the analysis of the experiments (Fig. 6). The layering predicted by the models is therefore consistent with the pattern seen in experimental welds, confirming that the tools stick to the workpiece for the majority of the process. Two refinements to the model are now explored: firstly, the effect of varying the stick-slip conditions at the top surface; and secondly, allowing the depth of the deformation zone to evolve with time.

The influence of the assumed stick-slip profiles on the weld patterns is clearest in vertical cross-sections, as shown in Fig. 13. The main effect is to change the position of the 'kink' in the layers, at the radial limit of sticking, where the layers turn towards the top surface. Profile 1 , with $r_{1}=0.9 R_{\mathrm{s}}$, imposes very intense deformation, as all the layers fall into a narrow outer slip region. Profile 2 broadens this zone somewhat, while Profile 3 , with a more progressive transition in slip velocity, leads to a smoother bowl-shaped pattern of layers. To be consistent with the experimental observations in Figs. 4 and 5, this suggests that the horizontal layering is associated with tool sticking, while in practice the slip zone will show a smooth velocity variation through a peak value and back to zero at the periphery.

The top-down views also reflect the assumed velocity profiles, although this is not a conventional metallographic section to take experimentally. However, selected samples were ground and polished back to a shallow depth to remove surface features left by the tool plunge and retraction. Fig. 14 shows an experimental top-down micrograph for a single-butt Al-steel weld, and the corresponding kinematic model prediction for velocity profile 3 after 10 rotations. The pattern is well-replicated, with a central zone in which the alloys remain separated, surrounded by tight spiral layers of the two Al alloys. This too suggests that the central sticking zone has a radius roughly half that of the shoulder. 

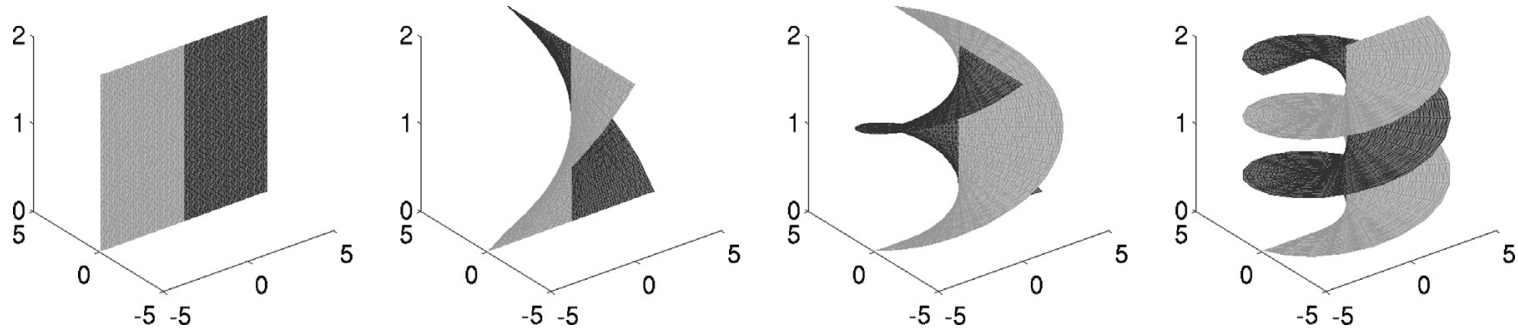

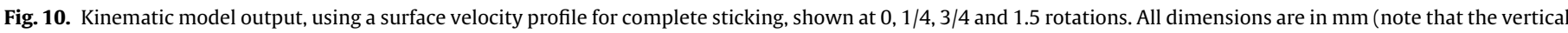
scale has been stretched for clarity).

(a)

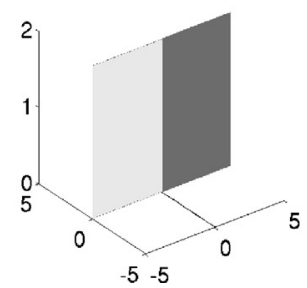

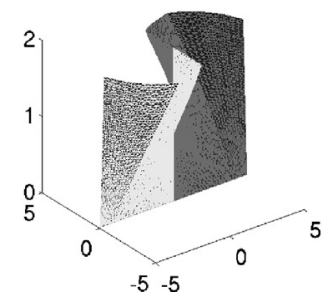

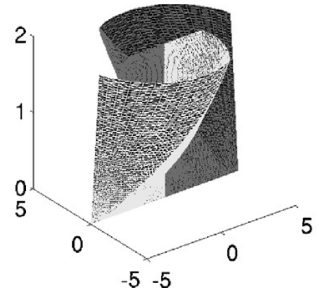

(b)

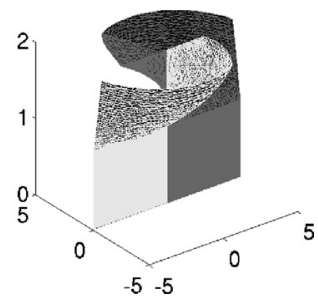

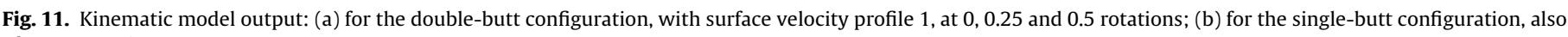
after 0.5 rotation.

\section{Number of rotations}
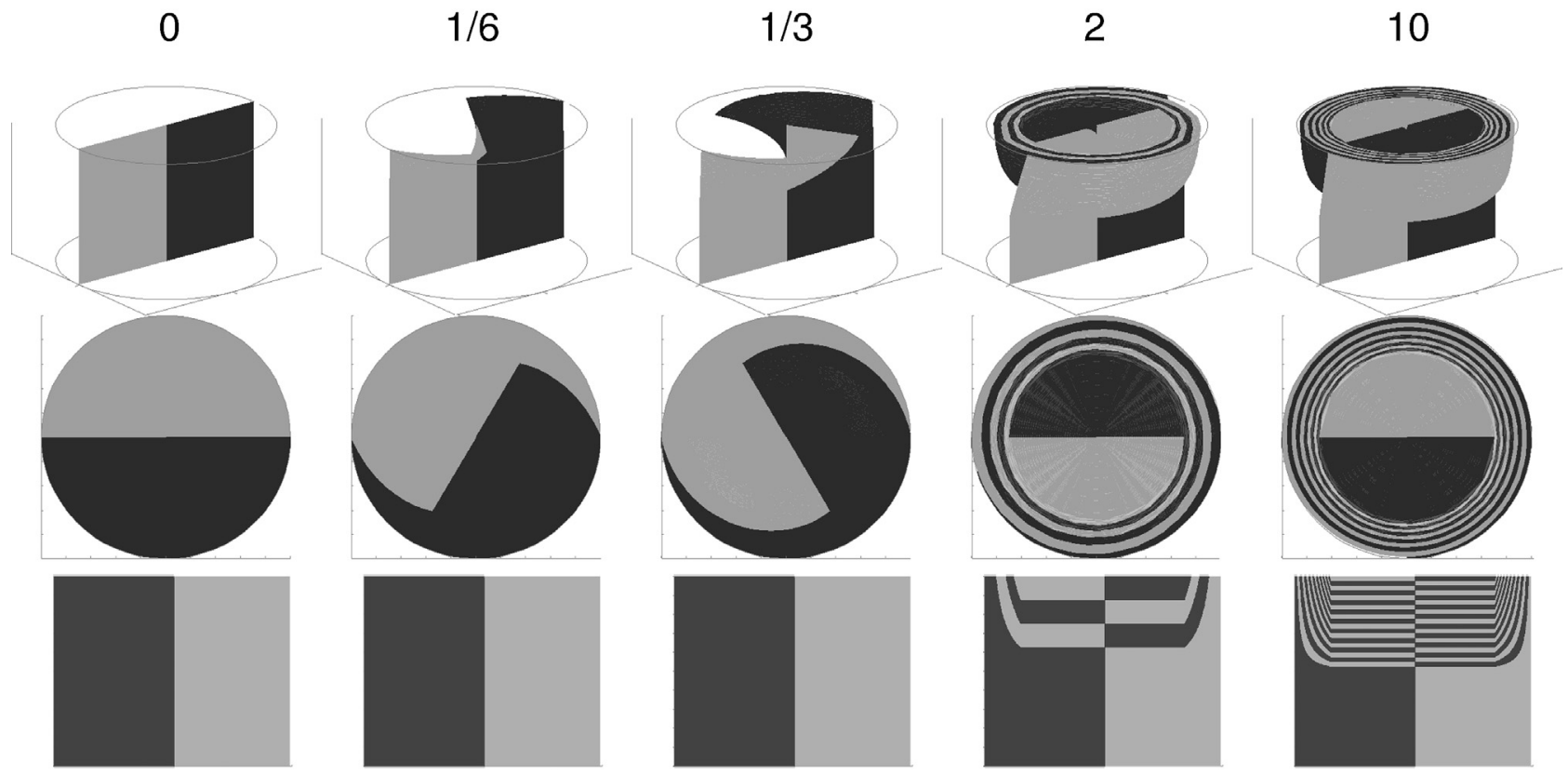

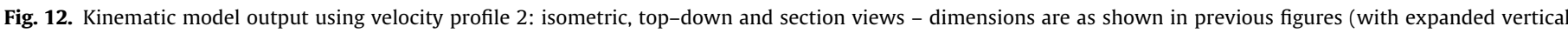
scale), omitted for clarity.

\subsection{Effect of progressive softening}

In the model so far, the deformation has been imposed throughthickness, with a linear gradient in velocity with depth, giving a constant circumferential shear strain-rate. In practice however, FSSW generates heat over the tool-workpiece interface, and the deformation progressively extends into the bulk of the material as it heats up and softens. For a tool radius that is much greater than the thickness, the heat flow is predominantly 1D in the throughthickness direction, giving approximately horizontal isotherms. A simple "softening law" has therefore been applied to capture the essence of this $z$-axis heat flow and the associated drop in strength with temperature, without recourse to thermal analysis. To simulate this, the depth of the deformation zone $h$ ' is assumed to increase linearly with time, $h^{\prime}=C_{1} t$. This continues until deformation reaches the backing plate (in an Al-Al weld) or the lower workpiece (in an Al-steel weld), after which time, $h^{\prime}=h$ and remains constant.

The process has two characteristic timescales, and it is helpful to quantify their relative magnitudes: (i) the time for one rotation $(=2 \pi / \omega)$; (ii) the characteristic heat flow time through the thickness, which $\approx h^{2} / a$ (where $a$ is the thermal diffusivity). We define the ratio of these times as a characteristic dimensionless group for the process: $\bar{\omega}=\frac{h^{2} / a}{2 \pi / \omega}=\frac{\omega h^{2}}{2 \pi a}$. It is expected that the time for 


\section{Number of rotations}

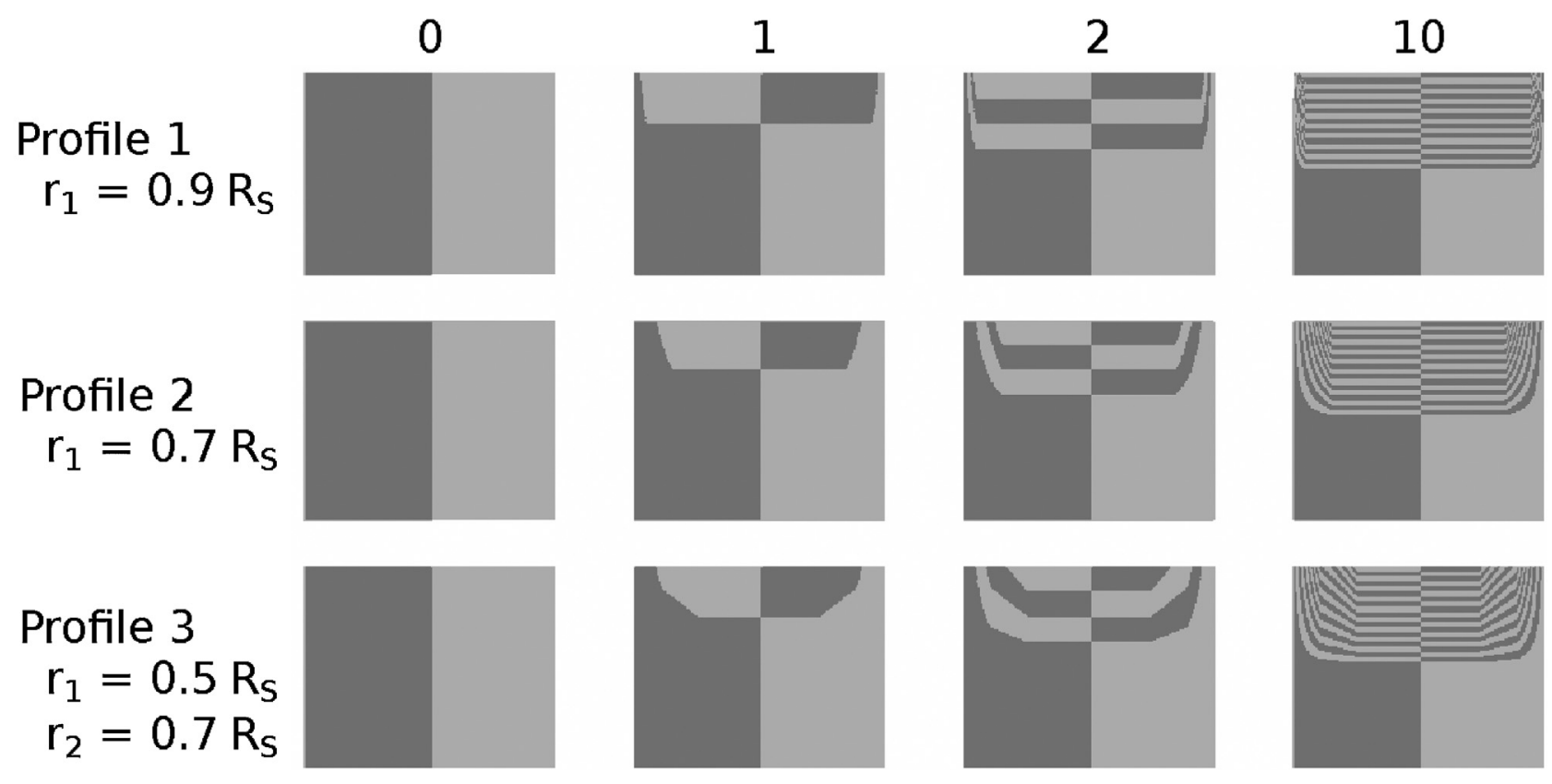

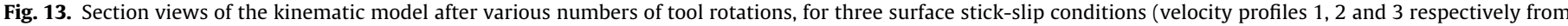
Fig. 7).
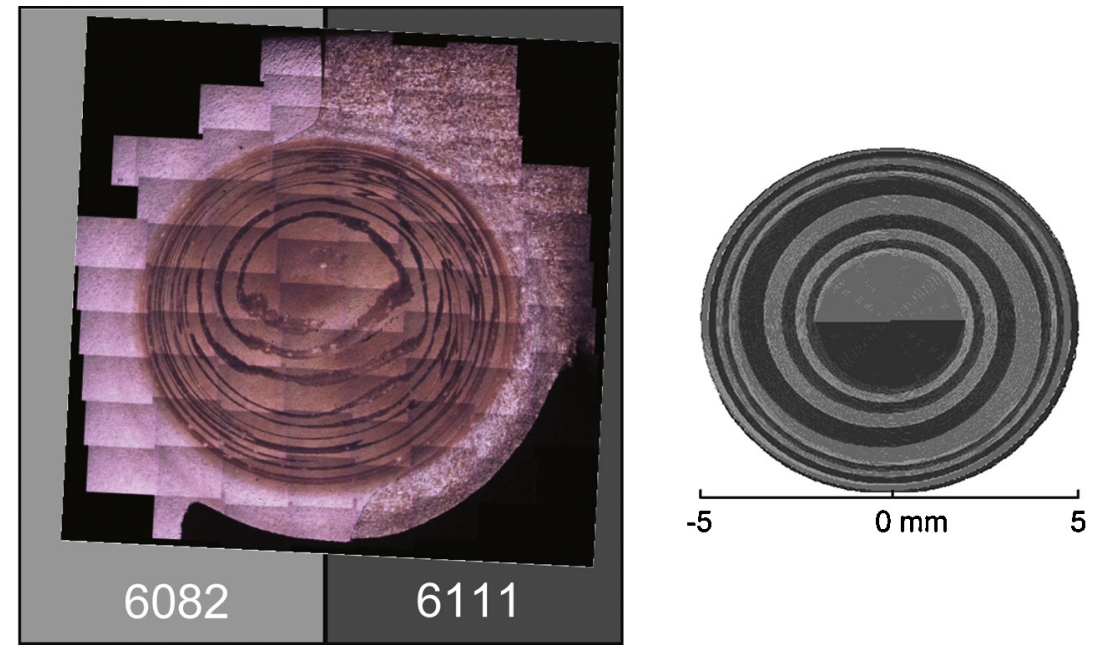

Fig. 14. A top-down micrograph for a single-butt Al-steel weld, and the corresponding kinematic model prediction, using velocity profile 3 and 10 tool rotations.

deformation to penetrate to the bottom surface, at thickness $h$, will scale closely with the heat flow timescale, that is, the constant $C_{1}$ is given by: $h / C_{1} \approx h^{2} / a$, or $C_{1} \approx a / h$. Hence the effect of the rate of softening with depth, characterised by $C_{1}$, can also be described by varying $\bar{\omega}$, that is, when $\bar{\omega}$ is of order unity, the deformation reaches the back face in approximately one rotation. For $\bar{\omega}>>1$, it takes many tool rotations for the deformation to penetrate the full thickness; and conversely, for $\bar{\omega}<<1$, through-thickness deformation is effectively immediate.

Fig. 15 shows cross-sectional views for various values of $\bar{\omega}$ using surface velocity profile 3 from Fig. 7. For values of $\bar{\omega}<<1$, the profiles in Fig. 15 are essentially the same as in Fig. 13, since the deformation depth reaches the mid-thickness limit in a fraction of a rotation. But as $\bar{\omega}$ increases, the progressive growth in deformation depth becomes apparent, with the deformation only penetrating through the top sheet in 10-20 rotations, for $\bar{\omega}=10$. A second change is more subtle: the total number of double layers remains equal to the number of rotations, but the thickness of the layers of the two alloys becomes non-uniform, with thinner layers nearer the surface - this is most apparent for example in the image for $\bar{\omega}=10$, after 10 rotations. A representative value of $\bar{\omega}$ may be found using typical values of $\omega, h$ and $a$ from the experiments: $\omega=2000 \mathrm{rpm}=209 \mathrm{rad} / \mathrm{s} ; h \approx 0.5 \mathrm{~mm}$, and $a=6.1 \times 10^{-5} \mathrm{~m}^{2} / \mathrm{s}$, giving $\bar{\omega}=14$, which is of similar order to the bottom row of Fig. 15, in which the variable layer thickness was apparent. So even though a linear rate of penetration of the deformation zone has been assumed in the model, it confirms the hypothesis from the experiments, that the observed increase in layer spacing with depth (Fig. 5) is associated with a deformation front progressively spreading through-thickness as the material softens as it heats up. 


\section{Number of rotations}

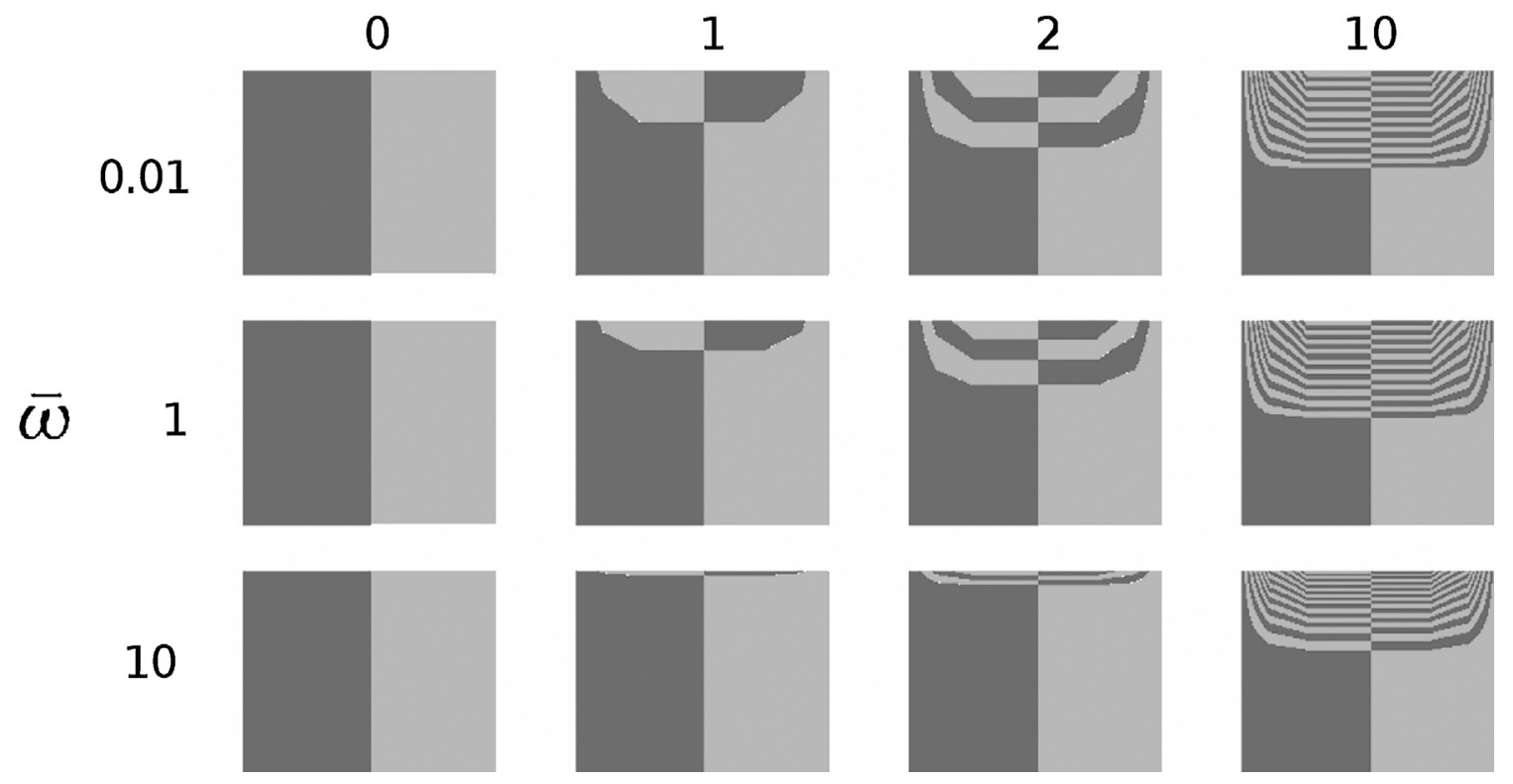

Fig. 15. Predicted section views for various values of $\bar{\omega}$ after increasing times, using slip profile 3 for the top surface.

\subsection{Modelling of Al-galvanised steel: effect of interface melting}

Finally, it was observed experimentally that welds between Al and galvanised steel produced a very different layering pattern in the single-butt configuration, and it was proposed that this was due to extensive slip at the interface between the sheets. The kinetic model is also able to provide visualisation of this behaviour.

First consider a cylinder of material in the top sheet of a singlebutt configuration Al-steel weld. A stick-slip velocity profile is imposed as before - here we use profile 3-with the zero velocity constraint imposed on the outer radius of the cylinder. But now the bottom interface is free to slip. As a result, there is no variation in the velocity field through the whole thickness - it is the same as that imposed by the tool, at all depths. But due to the constraint on the outer cylindrical surface, the two Al alloys are driven into spiral layers, now with their interfaces in the vertical direction - Fig. 16a shows these layers evolving at intervals up to 20 rotations. Note that the layers are confined to the outer slipping part of the tool, while the sticking region rotates as a rigid body attached to the tool. These vertical boundaries, concentrated towards the tool periphery, resemble those observed in the $\mathrm{Al}-\mathrm{Zn}$-coated welds.

In real welds, there must initially be some rotations of the tool before the $\mathrm{Zn}$ melts, since heat must be generated and conducted to the interface. So there may be some rotations before the onset of slipping, though because the $\mathrm{Zn}$ layer is soft, slip may be possible prior to melting. In the model, the transition in interface slip has been simulated by a two stage analysis: (a) an initial period with the lower interface sticking, generating some horizontal layering; (b) a switch to the second axisymmetric velocity field, with full slipping at the interface. Fig. 16b shows the resulting section though a model with the switch between mechanisms after an arbitrary 5 rotations, with 20 rotations in total. The treatment is crude, but suggests how it is possible to generate a combination of a central zone with horizontal layers, surrounded by thinner vertical layers - as observed experimentally in Fig. 7. Note that this occurred in the high rpm weld, but not in the low rpm weld-in the latter case the downforce was lower, so the interface may effectively slip from the start.

\section{Discussion}

Taken together, the experimental results indicate that from an early stage in the FSSW process, a sticking condition dominates over the central region of the tool surface. But due to the velocity discontinuity at the edge, between the tool peripheral velocity and the stationary surrounding material, there must be an annular slip region to provide a transition from the sticking velocity $(\omega r)$ at some radius down to zero. The correlation between the number of double layers in the dissimilar Al alloy welds and the number of tool rotations (Fig. 6) provided evidence that only a small proportion of the revolutions are required to obtain sticking. This implies that frictional heating rapidly softens the surface of the Al sheet, leading to seizure within a small number of revolutions. Compared to the flat tool, the fluted tools produce more complex deformation, with a superimposed inwards flow at the surface. But the overall conclusion is unchanged, with contact (and thus heat generation) governed by sticking contact with a peripheral slip region. It was also apparent that the interface between the sheets was effectively stuck, in both the Al-Al and Al-uncoated steel welds. In contrast, for the Al-galvanised steel, the presence of the soft $\mathrm{Zn}$ layer (which melts during welding) led to a rapid transition to low friction slipping at the interface between the sheets. The layering of the dissimilar Al alloys then becomes predominantly vertical rather than horizontal.

The kinematic modelling has confirmed these interpretations of the material flow. Material layering in the single-butt dissimilar alloy welds is achieved with purely circumferential flow, with no need to invoke radial flow. Horizontal layers in the cross-sectional views are associated with sticking to the tool, while the curve upwards towards a vertical orientation at the edge satisfies the boundary condition of zero velocity in the surrounding material. The model was also consistent with the near-surface plan views of the deformation region, with a central disc stuck to the tool, surrounded by spiral layers of material from initially opposing sides of the weld. In addition, the variation in layer thickness was consistent with a progressive increase in the depth of deformation with heating and softening of the Al sheets. This occurs because the thinner surface layers have made more circuits of the tool axis 

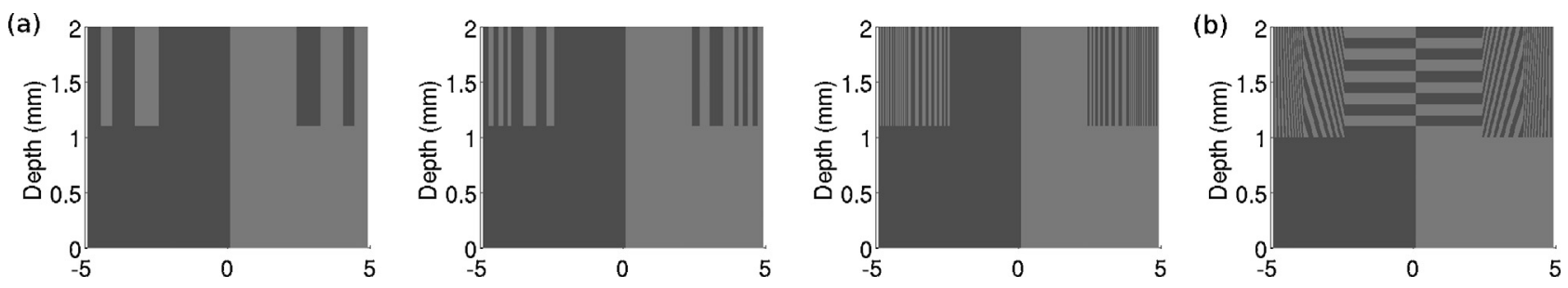

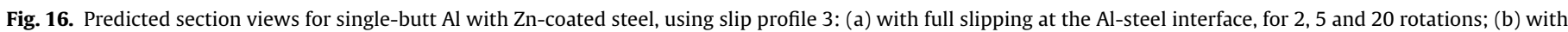
an initial 5 rotations of sticking at the Al-steel interface, followed by 15 rotations with full slipping.

than those at the base of the deformation zone, which started to deform at a later time. Finally it is apparent that increasing the tool plunge depth will not change this overall deformation pattern the cross-sectional pattern will be compressed to a thinner section, with radial expulsion of material at the edge to conserve volume.

These observations are of fundamental significance in friction stir processing generally, since the tool contact conditions, and the distribution of plastic deformation, directly control the heat generation rate and its spatial distribution. The review by Shercliff and Colegrove, 2007 shows that thermal modelling efforts in friction stir welding commonly assume a uniform friction condition over the whole shoulder area, with either sticking friction or Coulomb friction, or assume a distribution of power density at the tool interface that reflects an assumed underlying frictional contact. As the power input to the weld is rarely measured directly, experimental calibration is used to fit the friction conditions or power input to thermocouple data. But it is commonly found that the power input is over-estimated, which indicates that the slipping region has not been taken into account. In one CFD model developed by Colegrove and Shercliff (2006) and Colegrove et al. (2007), this was recognised and managed empirically by applying the heat generation over a reduced radius, typically $90 \%$ of the true shoulder radius. The simple kinematic model could not realistically be extended to incorporate the inwards radial and downwards flow induced by the fluted tools. Nonetheless it is apparent that there will be a (modest) additional contribution to plastic deformation in the swirl region, at a radius around $0.4-0.7$ of the tool radius. Jedrasiak et al. (2013) have used this observation to guide the calibration of the radial distributions of heat input in a thermal model developed for FSSW. This thermal model has shown that the differences in thermocouple data for welds with flat and fluted tools could be predicted successfully by using a different radial heat input distribution for each tool type. It should also be noted that the observation that tool sticking drives the deformation implies that the metal flow and heat generation are closely tied to the material hot flow strength. Shercliff and Colegrove (2007) noted that as the surface approaches its solidus temperature, the maximum possible interface shear tractions will fall rapidly, so the heat input is self-regulating in friction stir processing.

The deformation patterns also govern the formation of metal-metal bonding at the sheet interface and hence the joint strength and failure energy. In $\mathrm{Al}-\mathrm{Al}$, the two layers are effectively stuck under the high pressure below the tool, so deformation propagates continuously through the interface as if it is a single workpiece (provided the process conditions give enough heat input and time for plasticity to extend to that depth). The interface remains fairly flat with a flat tool, but is deformed by the fluted tools - producing a "hook" of lower sheet material which eventually protrudes right through the upper sheet to the tool interface, pushing the interface downwards in the weld centre. This stretches the bond line, exposing new clean surface and contributing to break-up of the oxide layer - though in FSSW the normal strains parallel to the interface are modest, so oxide break-up and metal-metal bonding relies on intense shear deformation of material on both sides of the interface. Hooking however has the negative impact of orienting a relatively weak interface perpendicular to the tensile stress in a loaded lap-shear joint.

In the Al-uncoated steel welds, the interface cannot be reshaped by hooking, due to the higher strength of the steel at the weld temperatures, so intense shear is limited to the deforming Al layer, with a sticking condition at the weld interface. Hence the relative motion across the interface between the top and bottom sheets is limited, which accounts for the relatively poor performance of these joints. Al-uncoated steel FSSW with this tool arrangement is perhaps therefore effectively a process of diffusion bonding, facilitated by frictional heating and a high interface pressure. The deformation zone must penetrate to the bottom of the top sheet, as it is much more difficult to disrupt the oxide contaminated surfaces of both materials when one does not deform.

In contrast, in the welds produced with $\mathrm{Al}-\mathrm{Zn}$ coated steel, the deformation of the Al layer was much less over most of the interface below the tool, as the $\mathrm{Zn}$ layer provides effectively no resistance, as it melts during welding, giving a sliding condition at the interface. Nonetheless, expulsion of most of the $\mathrm{Zn}$ could be achieved with slower processing times, leading to a joint strength that was superior to the uncoated case, and comparable to that of the Al-Al joints. These welds should perhaps be considered to be $\mathrm{Zn}$-brazed joints rather than solid-state welds, with the lap shear strength being largely due to the high degree of constraint imposed on the thin interfacial layer of solidified Zn-rich liquid.

Finally, in Al-steel (and other dissimilar alloy) FSSW, the radial variation of both deformation and temperature will govern the formation and thickness of intermetallic reaction layers, and microstructural changes in the precipitation hardened Al-6111 alloy, both of which are also critical to joint performance. Modelling efforts such as those by Jedrasiak et al. (2013) aim to predict the temperature distribution in the heat-affected zone, and at the weld interface, to interpret and model these microstructural changes. These thermal models use surface heating distributions guided by the kinematic interpretation of contact conditions provided in this paper.

\section{Conclusions}

The material flow in friction stir spot welding of $\mathrm{Al}$ to $\mathrm{Al}$, and $\mathrm{Al}$ to steel, has been investigated experimentally and simulated with a kinematic modelling approach. The differential etching response of dissimilar Al alloys in the joints revealed how material from the two sides of the weld becomes inter-layered, depending on the tool design, welding conditions, and surface coating of the steel sheet. The main conclusions of the experiments were that:

- metal flow in FSSW is predominantly circumferential (with fluted tools adding a degree of inward radial flow at the surface);

- the central region of the workpiece sticks to the tool, with a slip region towards the outer periphery (for compatibility with the stationary surrounding material); 
- sticking appears to be achieved in very few rotations after initial contact of the tool.

A novel kinematic model was developed assuming purely circumferential flow, providing a consistent interpretation of the experimental observations. The model illustrated:

- the importance of the surface velocity profile imposed by the tool, and the kinematic need for a stick-slip boundary within the toolworkpiece contact area;

- the progressive increase in the depth of the deformation zone with time, due to progressive heating and material softening.

The interpretation of the tool-workpiece contact in friction stir processing has been debated at length since the first development of FSW. The results in this paper inform the handling of this contact, and the related heat input distribution, in thermal modelling of friction processing.

\section{Acknowledgements}

The authors wish to thank the EPSRC for funding this research through the following grants: Friction Joining - Low Energy Manufacturing for Hybrid Structures in Fuel Efficient Transport Applications (EP/G022402/1 and EP/G022674/1); and LATEST2, Light Alloys Towards Environmentally Sustainable Transport (EP/H020047/1). We are also grateful to Mike Shergold (Jaguar Land Rover Group), and Andrew Smith and Andrew Beedles (Corus) for provision of materials.

\section{References}

Bakavos, D., Babout, L., Prangnell, P., 2010. Optimisation of short cycle time friction spot welding of thin aluminium automotive sheet. In: Proc. 8th Int. Friction Stir Welding Symposium, S7A, 18-20 May 2010, Timmendorfer Strand, Germany, pp. 546-554.

Bakavos, D., Chen, Y.C., Babout, L., Prangnell, P.B., 2011. Material interactions in a novel pinless tool approach to friction stir spot welding thin aluminum sheet. Metall. Mater. Trans. A 42 (May (5)), 1266-1282.

Bakavos, D., Prangnell, P.B., 2009. Effect of reduced or zero pin length and anvil insulation on friction stir spot welding thin gauge 6111 automotive sheet. Sci. Technol. Weld. Joining 14 (5), 443-456.

Bozzi, S., Helbert-Etter, A.L., Baudin, T., Criqui, B., Kerbiguet, J.G., 2010. Intermetallic compounds in Al 6016/IF-steel friction stir spot welds. Mater. Sci. Eng. A527, 4505-4509.
Briskham, P., Blundell, N., Han, L., Hewitt, R., Young, K., 2006. Comparison of Self-pierce Riveting, Resistance Spot Welding and Spot Friction Joining for Aluminium Automotive Aheet. SAE World Congress \& Exhibition, Detroit, MI USA, http://dx.doi.org/10.4271/2006-01-0774, April.

Chen, Y.C., Haddadi, F., Prangnell, P.B., 2010. Feasibility study of short cycle time friction stir spot welding thin sheet Al to ungalvanised and galvanised steel. In: Proc. 8th Int. Friction Stir Welding Symposium, S10B, 18-20 May 2010, Timmendorfer Strand, Germany, pp. 893-903.

Coelho, R.S., Kostka, A., dos Santos, J.F., Pyzalla, A.R., 2008. EBSD technique for visualization of material flow in aluminum to steel friction-stir dissimilar welding. Adv. Eng. Mater. 10 (12), 1127-1133.

Colegrove, P.A., Shercliff, H.R., 2006. CFD Modelling of the friction stir welding of thick Plate 7449 aluminium alloy. Sci. Technol. Weld. Joining 11 (4), 429-441.

Colegrove, P.A., Shercliff, H.R., Zettler, R., 2007. A model for predicting the heat generation and temperature in friction stir welding from the material properties. Sci. Technol. Weld. Joining 12, 284-297.

Connolly, C., 2007. Friction spot joining in aluminium car bodies. Ind. Rob. Int. J. 34/1, 17-20.

Jedrasiak P., Reilly A., Shercliff H.R., McShane G.J., Chen Y.C., Prangnell P., 2013. Thermal modelling of Al-Al and Al-steel friction stir spot welding, Mathematical Modelling of Weld Phenomena 10 (eds. Sommitsch C. and Enzinger N.), Verl. der Techn. Univ. Graz, Austria, 477-498.

Lee, C.Y., Choi, D.H., Yeon, Y.M., Jung, S.B., 2009. Dissimilar friction stir spot welding of low carbon steel and Al-Mg alloy by formation of IMCs. Sci. Technol. Weld Joining 14 (3), 216-220.

Murray, J.L., 1986. In: Massalski, T.B. (Ed.), Binary Alloy Phase Diagrams. ASM, Materials Park, OH, USA, p. 185.

Qiu, R., Iwamoto, C., Satonaka, S., 2009. Interfacial microstructure and strength of steel/aluminum alloy joints welded by resistance spot welding with cover plate. J. Mater. Process. Technol. 209 (8), 4186-4193.

Reilly, A., 2013. Modelling of Friction Stir Spot Welding, PhD thesis. University of Cambridge, UK

Sakiyama, T., Naito, Y., Miyazaki, Y., Nose, T., Murayama, G., Saita, K., Oikawa, H., 2013. Dissimilar Metal Joining Technologies for Steel Sheet and Aluminium Alloy Sheet in Auto Body. Nippon Steel Technical Report, No. 103. Welding \& Joining Research Center, Chiba 293-8511, 91-98.

Sato H., Shioda A., Konakawa H., Nakagawa N., Miyamoto K., 2009. National Meeting of the Japan Welding Society 84, 202-204.

Shercliff, H.R., Colegrove, P.A., 2007. In: Mishra, R.S., Mahoney, M. (Eds.), Process Modeling. Friction Stir Welding and Processing. ASM, Materials Park, OH, USA, pp. 187-217, March.

da Silva, A.A.M., Aldanondo, E., Alvarez, P., Echeverrua, A., 2010. Dissimilar joining of AA1050 aluminium alloy and hot-stamped boron steels using friction stir, friction stir spot welding and friction stir shoulder welding. In: Proc. 8th Int. Friction Stir Welding Symposium, S10B, 18-20 May 2010, Timmendorfer Strand, Germany, pp. 877-892.

Uematsu, Y., Tokaji, K., Tozaki, Y., Nakashima, Y., 2010. Fatigue behaviour of dissimilar friction stir spot weld between A6061 and SPCC welded by a scrolled groove shoulder tool. Procedia Eng. 2, 193-201.

Watanabe, M., Matsumoto, H., Feng, K., Nakamura, Y., Kumai, S., 2010. Effect of tool shape on interfacial microstructure of friction stir spot welded aluminium/steel lap joint. In: Proc. 8th Int. Friction Stir Welding Symposium, S10B, 18-20 May 2010, Timmendorfer Strand, Germany, pp. 904-909. 